\title{
Knowledge translation strategies to improve the resources for rehabilitation counselors to employ best practices in the delivery of vocational rehabilitation services
}

\author{
John Lui*, Catherine A. Anderson, Priscilla Matthews, Erin Nierenhausen and Amanda Schlegelmilch \\ University of Wisconsin-Stout, Menomonie, WI, USA
}

Revised/Accepted July 2014

\begin{abstract}
The purpose of this article is to acknowledge the gap between research and practice in vocational rehabilitation (VR) and provide strategies for VR counselors to help bridge that gap. Evidence-based practice (EBP) and knowledge translation (KT) are two concepts that help the implementation of research into practice and have been adopted in health care and other related fields for many years. Although most research supports the implementation of these theories in health care settings, it is a fairly new concept in vocational rehabilitation. Many barriers, such as inadequate time, limited access to technology and research, and caseload size can inhibit the implementation of EBP and KT for VR counselors. The Knowledge-to-Action (KTA) framework helps to overcome some of these barriers and facilitate counselors' abilities to acquire, apply, and share knowledge and evidence-based approaches. More strategies for facilitating KT and EBP implementation for VR counselors are reviewed.
\end{abstract}

Keywords: Knowledge translation, vocational rehabilitation, evidence-based practice

\section{Introduction}

The identification and use of evidence-based practice (EBP) has existed in health care, public health, and related fields for several decades. Yet, the concepts of EBP and knowledge translation (KT) are relatively recent in vocational rehabilitation (VR). While vocational rehabilitation counselors report interest in acquiring and applying evidence-based knowledge, they clearly and consistently note time constraints and technology limitations as barriers in this process (Anderson, Matthews, Lui, \& Nierenhausen, in press; Bezyak, Kubota, \& Rosenthal, 2010; Chan, et al., 2010). State VR agencies can address organizational issues including time management, caseload size,

*Address for correspondence: Dr. John Lui, Stout Vocational Rehabilitation Institute (SVRI), University of Wisconsin-Stout, Menomonie, WI 54751, USA. E-mail: LuiJ@uwstout.edu. access to technology, and technology literacy. However, rehabilitation researchers must also acknowledge these obstacles, and enhance understanding and use of effective knowledge translation strategies in order to address practitioner concerns and support increased application of evidence-based practices in the field.

Using the Knowledge-to-Action (KTA) process or similar framework to better understand, conceptualize, and further study the facilitators and barriers involved in VR counselors acquiring, applying, and sharing knowledge is important in order to support and sustain evidence-based approaches to VR practice.

\section{1. $E B P$ and $K T$}

Evidence-based practice (EBP) as described by Chan et al. (2010) has five hierarchical levels of evidence based on the design and rigor applied. Level 1 
consists of strong evidence from at least one systematic review of multiple well-designed randomized controlled trials. Level 2 consists of strong evidence from at least one properly designed randomized controlled trial of appropriate size. Level 3 consists of evidence from well-designed trials without randomization, single group pre-post, cohort, time series, or matched case-controlled studies. Level 4 consists of evidence from well-designed non-experimental studies from more than one center or research group; and Level 5 evidence consists of opinions of respected authorities, based on clinical evidence, descriptive studies, or reports of expert committees.

$\mathrm{KT}$ is defined as "the multidimensional, active process of ensuring that new knowledge gained through the course of research ultimately improves the lives of people with disabilities and furthers their participation in society" (U.S. Department of Education, 2006, p. 8195). To ensure that new knowledge gained through research impacts the lives of people with disabilities, information needs to be created and delivered in a format and system that is easily accessible by vocational rehabilitation practitioners. As stated by Pettus-Davis, Grady, Cuddeback, and Scheyett (2011), "the practitioner is the vehicle through which an intervention is translated from a description in a book or an article to an active process with a client" (p. 380).

The two main components to the KnowledgeTo-Action (KTA) model are: knowledge creation and the action cycle. Knowledge creation consists of three phases that include: knowledge inquiry, knowledge synthesis, and knowledge tools or products (Graham et al., 2006). The phases work together to condense the knowledge into only what is needed and relevant for implementation.

\subsection{KT and KTA in vocational rehabilitation}

Researcher-practitioner partnerships and relationships are critical in all aspects of intervention research, dissemination and implementation research, and dissemination and implementation of results (Baumbusch et al., 2008; Kerner, 2006). Historically, the transfer of research findings used linear, unidirectional, and passive flows of information from research to practice. More recently, with the emergence of knowledge translation, an increasing number of scholars have noted that models have begun to address the gap between research and practice (Baumbusch et al., 2008). Within knowledge translation frameworks, researchers are no longer viewed as experts with knowledge to convey to practitioners as passive learners. Practitioners and researchers, working collaboratively, can ensure that new evidence-based interventions are informed by contextual knowledge and practical experience (Kerner, 2006). Consistent with participatory approaches, researchers and practitioners must work together to identify areas of need, conduct research, and apply results in the field through interactive knowledge transfer processes (Baumbusch et al., 2008).

Rehabilitation researchers can benefit from knowledge translation work that has already taken place in other fields and recognize that traditional continuing education to promote research uptake has achieved little beyond changing practitioners' awareness of the evidence (McWilliam, 2007). A key challenge in KT involves taking a sizeable body of research-based knowledge and converting it into meaningful and useful information to the user audience (Baumbusch et al., 2008). Therefore, knowledge translation activities must focus as much on process as on product and emphasize the crucial elements of reciprocity and exchange between the producers and users of knowledge (Jacobson, Butterill, \& Goering, 2003).

\section{Objectives of KT: Acquire, apply, and share}

One of the primary objectives of knowledge translation (KT) processes is to get evidence-informed and evidence-based practices into the hands of practitioners in formats that are easy to access, use, and share. No single KT strategy applies across all settings; strategies must be aligned with the desired message and change or action in the field (Grol, 2001; Grol \& Grinshaw, 2003). It is also important to acknowledge the social and cultural contexts when applying evidence-based research. Recognizing these important variables can help researchers better understand and distinguish how and when practitioners use their experiential knowledge in implementing evidence-based practices (McWilliam, 2007; Sudsawad, 2007). This information may provide researchers with distinctive considerations for further developing and sustaining successful KT strategies.

Various models depicting knowledge development, synthesis, and dissemination are used across fields. While knowledge translation is a relatively new concept for both researchers and vocational rehabilitation practitioners, the Knowledge-to-Action (KTA) process framework developed by Graham et al. (2006) is emerging as a relevant model that appears to fit well with the field of vocational rehabilitation. The KTA involves 
a knowledge creation cycle involving inquiry, synthesis, and tool or product development. Participatory approaches to research are critical in informing a solid knowledge creation cycle. Additionally, an action cycle is present within KTA that involves knowledge application and considers contextual factors, identifying barriers to knowledge use, tailoring interventions based on context and barriers, monitoring knowledge use, evaluating outcomes, and determining sustainability aspects (Graham et al., 2006).

Given that KT involves actions and interactions between researchers and practitioners, barrier identification, and contextual issues, it is imperative to consider both individual and organizational factors when studying and discussing effective knowledge translation methods and the factors necessary to support and sustain such approaches within vocational rehabilitation systems. Not only must counselors have easy access to evidence-based information, they must be working in environments that support and encourage application and sharing of such practices (Anderson et al., in press).

\subsection{Vocational Rehabilitation (VR) counselors and $K T$}

Rehabilitation researchers need to understand just how much and at what level VR counselors have access to evidence-based research, understand its value, and integrate it into work practices (Graham et al., 2013). While research can provide solutions, it must be readily available and easily accessible to vocational rehabilitation counselors in order to be useful.

Therefore, in the application of the knowledge-toaction (KTA) process as the knowledge translation platform, the knowledge creation phase must be completed to discover the level of awareness and interest in acquiring, applying, and sharing new knowledge prior to VR counselors taking action (the knowledge action cycle) in these areas (Graham et al., 2006). In a recent study focusing on knowledge translation among over 800 counselors working in the federalstate vocational rehabilitation program, the authors identified relationships highlighting the importance of acquisition, application, and sharing of evidencebased knowledge among practitioners (Anderson et al., in press). Moderate, yet significant, relationships exist between VR counselors' interest in acquiring and applying evidence-based practice in vocational rehabilitation settings $(\rho=.43 ;<.001)$, and interest in applying and sharing evidence-based practice in vocational rehabilitation settings $(\rho=.40 ;<.001)$. The study also found that $96.3 \%$ of VR counselors reported an interest in acquiring and $99 \%$ reported interest in applying new knowledge that promotes evidence-based practice in vocational rehabilitation (Anderson et al., in press). Similar results identified through a separate study indicate the majority (84.2\%) of VR staff value research for practice (Graham et al., 2013).

Assessing perceived barriers to knowledge acquisition and application is important in understanding and differentiating between individual and organizational factors that may limit access to information and resources. The barriers to accessing or acquiring knowledge about evidence-based practices most commonly cited by practitioners include: cost and insufficient agency/organization resources, lack of availability to research, lack of relevant research, having no time or opportunity to find or use research evidence, and policymakers' and other users not being skilled in research methods (Anderson et al., in press; Baumbusch et al., 2008; Graham et al., 2013; Oliver, Innvar, Lorenc, Woodman, \& Thomas, 2014).

The preferred formats for acquiring and sharing research information appear to be informal, nonacademic, and relatively short in duration. Strategies identified by VR counselors include summaries of findings, face-to-face training, online asynchronous (non-interactive) training, and training conferences (Anderson et al., in press; Graham et al., 2013). Anderson et al. (in press) found that $96.3 \%$ of VR counselors reported an interest in sharing new knowledge; however, researchers still tend to disseminate results primarily through academic channels such as peer-reviewed publications and conferences. Although $87 \%$ of VR counselors report understanding the fundamental definition of "evidence", $40.5 \%$ also report that academic articles did not clearly describe how to implement EBP therefore limiting their utility for practice (Graham et al., 2013). As researchers, it is important to understand the fundamental tenets of knowledge translation and the need to engage VR practitioners at the point of care. As Baumbusch et al. (2008) note, the aim is to build knowledge uptake activities by reframing our knowledge transfer strategies to include responsive dialogue between researchers and practitioners and be fine-tuned to the types of decisions and decisionmaking environments in which practitioners work.

Consistent with the purpose of Communities of Practice $(\mathrm{CoP})$ as defined by Wenger, McDermott, and Snyder (2002) a majority of the VR counselors surveyed by Anderson et al. (in press) also expressed their desire to join a CoP "to openly discuss and exchange 
feedback with other VR practitioners on issues related to VR practice" (75.8\%) and "to gain access to EBP and other information that could improve employment outcomes for people with disabilities (72.6\%)." These respondents also indicated a preference for monthly participation, followed by weekly participation for a preferred length of time ranging from less than an hour to 3-4 hours.

\section{Strategies and implementation experiences}

The information gained from Anderson et al. (in press) was employed by the Rehabilitation Research and Training Center (RRTC)-EBP, when implementing the second phase of KTA, the action cycle, in developing and disseminating knowledge as desired and preferred by the VR counselors. According to a systematic review conducted by Menon, Korner-Bitensky, McKibbon, and Straus (2009) active multi-component KT interventions improved EBP and practice behaviors compared with passive strategies in a clinical setting. This RRTC, therefore, developed a website to use as the portal to access innovative knowledge and newly developed tools based on sound research. The known issues of all stakeholders impacted by the use of EBP in VR were acknowledged and an invitation to all stakeholders to interact with RRTC researchers was issued. Stakeholders included professionals and practitioners, researchers and academicians, policymakers and administrators, business and industry, and people with disabilities and their families. Stakeholders were invited to maintain contact with the RRTC through social media, a quarterly e-newsletter, RSS feed, and listserv, and were offered access to technical support through the website, e-mail, and a toll-free phone number.

As suggested by Sudsawad (2007) a multimodal, multidirectional approach was taken to translate and disseminate knowledge to increase effectiveness. Strategies included: interactive web-based plain language summaries, a series of brief quizzes, self-paced asynchronous training modules, face-to-face training to both professionals and students, a self-evaluation tool to guide a critical approach to applying EBP, email marketing of a quarterly newsletter, strategic use of social media, and the development of communities of practice. Participant interaction with researchers and other practitioners was invited for each of these modes.

To enable stakeholders to easily acquire and apply relevant research resulting from the RRTC, webbased plain language summaries were developed
(Schünemann et al., 2011) that focused on information indicated as most important to practitioners in the KT study: the population and practice effected by the research, a description of the problem and how the research presented could be used as a targeted intervention, access (web-based links) to full articles and additional sources of information, and the option of asking questions directly of researchers involved in the project via the website. In addition, readers were encouraged to share comments with other readers, rate each summary on a 5-star scale, and rate the summary for use by the RRTC in evaluating the summary's effectiveness.

Based on feedback gained from VR practitioners on their preferences for receiving information, additional modes to enable stakeholders to acquire and apply new knowledge included brief web-based training modules that were self-paced and available at any time. Training topics included: levels of evidence-based practice, integrating research into VR practice (with an accompanying tool for practitioners to use to guide and evaluate their integration of EBP into their own practice), and developing communities of practice (Anderson et al., in press). A series of brief quizzes designed to inform and pique interest in EBP was also developed.

Web-based information was disseminated to VR professionals through a quarterly e-newsletter as well as through the strategic use of social media, specifically Facebook, Twitter, YouTube, and LinkedIn to enable stakeholders to acquire and apply new knowledge related to EBP in VR. Although emphasis was given to disseminating knowledge developed by the RRTC-EBP VR and linking stakeholders to the RRTC website, additional resources related to EBP in VR were also disseminated using these mediums. The "share" feature on Facebook and LinkedIn, and the "Re-tweet" feature on Twitter were used by stakeholders to share information disseminated by the RRTC.

The social mediums selected by the RRTC-EBP VR supported the following categories of activities related to laying a foundation for a community of experts and online collaboration: collaboration, promotion of one's work, building peer networks, and extracting or organizing information (Coppock \& Davis, 2013). The RRTC-EBP VR website, as the repository of information related to evidence-based and best practices, was linked in posts to enable stakeholders to extract information and interact with researchers.

Face-to-face interaction was also used as a mode of enabling stakeholders to acquire and apply new knowledge, a mode positively identified by VR practitioners 
as a means of acquiring information related to EBP (Anderson et al., in press). In response to the need identified by Martin and Martin (1989) to better prepare students to become "consumers of research in order to use research to improve practice" (p. 491), the RRTC-EBP VR used an upstream approach to engage graduate-level rehabilitation students and future practitioners at leading universities using an interactive "workshop" format. Strong relationships were established with professional associations to lay a foundation of community-based research as suggested by Hergenrather, Geishecker, McGuire-Kuletz, Gitlin, and Rhodes (2010). As a result, frequent presentations were made at state and national rehabilitation practitioner conferences and rehabilitation education conferences, and dialogue took place between the RRTC and community service providers. Feedback received by participants was welcomed and incorporated into dissemination practices.

In response to survey respondents' expressed interest in participating in a community of practice $(\mathrm{CoP})$ and a forum for peer-to-peer sharing of information, a 3-month pilot was launched in August of 2013. Technology, online learning, and information sharing options are key in developing and maintaining effective learning communities. CoPs encourage the translation of knowledge into action and provide a framework for information sharing, competence development, rich discussion, and mentoring. Hence, CoPs facilitate the creation, organization, revision, and sharing of knowledge among members of the community (Seaman, 2008).

The RRTC's pilot CoP focused on how CoPs could be used by VR practitioners to bridge the gap between research and practice in VR. It was used as a participatory action tool to assist the RRTC in developing effective knowledge, tools, and training materials. Nine VR professionals participated in this pilot CoP: state/federal and private practitioners, researchers, educators, and business leaders, among whom were individuals with disabilities. Evaluative surveys conducted during and after this pilot indicated that the CoP experience impacted participants' intention to acquire, apply, and share information related to EBP in VR in the future, and that participants did acquire, apply, and share information as a result of their participation. Participants expressed that participation was a challenge: this pilot CoP began with 9 active participants in month 1 , and ended with 2 active participants at the close of the CoP. Reasons were not given for lack of participation.
To expand information dissemination and participatory action research activities to include all stakeholders, the RRTC-EBP VR chose to use LinkedIn as the primary platform for online learning communities. LinkedIn is a form of social media that is easily accessible and requires little learning, two characteristics identified as being supportive of collaboration among researchers. It also offers identification and verification of participants, identified as elements that provide an adequate level of trust critical to online interaction (Coppock \& Davis, 2013). In addition, LinkedIn's member-only groups, in which discussions can be seen only by those group members offer a further level of participant screening that may be needed to preserve stakeholder trust. LinkedIn's sub-group feature also offers the ability to host member-only small learning communities in specific areas of interest.

\section{Discussion}

An important aspect to stakeholder satisfaction is involving the stakeholders in the different research decisions, such as: defining the issue, development, facilitation, outcomes, evaluation, and dissemination (Hergenrather et al., 2010; Chan et al., 2011). The participatory action approach between the researchers and the stakeholders may ensure that the knowledge generated is significant and applicable to all stakeholders that are involved, as well as the researchers (Graham et al., 2006). This method should help the stakeholders to have more of an investment and commitment to the research, especially in application and dissemination of the results.

Interestingly, this participatory action approach parallels the business management philosophy termed "the marketing concept" which has been highly utilized in business and industry (Pfeffer \& Salancik, 1978; McCarthy, 1960). The marketing concept is based on the premise that over the longer term, "the market creates, shapes, and defines the demand for all classes of products and services" (Marshall, 1984, p. 1). This customer-focused approach maintains that the starting point is always the customer. Therefore, every aspect of a market offering, including the nature of the product itself, is defined in terms of what the customer demands and expects.

This contemporary customer-focused approach is known as SIVA (Solution, Information, Value, and Access). This system is basically the four Ps (Product, Promotion, Price, and Place) renamed and reworded 
to provide a customer focus. According to Dev and Schultz (2005b) the essence of SIVA is to: "develop and manage Solutions, not just Products, offer Information instead of Promotion, create Value instead of obsessing with Price, provide Access wherever, whenever, and however the customer wants to experience the solution rather than merely where to Place products" (p. 38).

As applied to the KTA model, the demand-based SIVA concept places the multiple KT stakeholders at the beginning of the KT (marketing) process. With an understanding of the stakeholders' issues, Solutions are the evidence-based knowledge, skills and techniques necessitated to resolve those issues; Information is the specified quantity, intensity, and style of those data and elements to be received; Value is the perceived satisfaction and usefulness of the acquired facts and attempted tools for the energy and time invested; and Access is the convenience and ease in obtaining these specifics and details (Dev \& Schultz, 2005a). Therefore, defining, designing, and delivering these combinations are the key challenges to knowledge translation. As continuous feedback is needed in SIVA for the customers, formative evaluations are required in KTA to sustain the desired level of engagement with the stakeholders and to assure that knowledge is being received and applied that will make positive impacts on employment outcomes for persons with disabilities.

\subsection{Formative evaluation}

Evaluation of strategies is essential to find out if and how the strategy is working and uncovers what is not working so improvement or modifications can be made. Monitoring the knowledge use or application helps to determine the effectiveness of the strategies so that the intervention can be adjusted as needed (Sudsawad, 2007). An evaluation needs to be conducted to determine if the application of knowledge had an influence on the intended population. Ongoing engagement with the stakeholders will provide valuable feedback for successful implementation of the KTA process to promote the application of knowledge relevant to the needs of the intended population (Chan et al., 2011).

As suggested by Sudsawad (2007) and described in this article, a multimodal, multidirectional approach was taken to translate and disseminate knowledge to increase KT effectiveness. Initial feedback and participation by stakeholders is promising as measured by: a) requests to join the RRTC-EBP VR mailing list, b) "likes" "shares" of posts related to plain language summaries and other sources of evidence based and promising practices, c) steadily increasing requests to join the RRTC-EBP VR's LinkedIn discussion group, and d) increasing frequency of external initiation of discussion topics.

Materials developed by the RRTC and made available on the website including plain language summaries, training modules, tools, and partner resources. The website itself is also evaluated by users using the following methods: a five-star rating scale attached to each plain language summary, a brief questionnaire asking users' intention and action to acquire, apply, and share relevant knowledge, the option of leaving comments and questions, and direct access to researchers through "Ask the Expert." Feedback to materials and tools are used to adjust the content and/or format to better meet the needs of the VR professionals. These ongoing formative evaluation activities enable the RRTC-EBP VR to monitoring stakeholders' knowledge use or application, and thus determine the effectiveness of strategies used so that interventions can be adjusted as needed (Sudsawad, 2007).

\subsection{Implications for EBP in VR practice}

Knowledge translation has multiple aspects to be considered when implementing the different strategies. The most recognized component of KT is that it encompasses all the steps between the creation of new knowledge and its application into practice (Sudsawad, 2007). Another essential aspect of KT is that it is an interactive and ongoing process between those who create the knowledge and those who will use and apply the knowledge. KT involves multiple activities and is a nonlinear process. It also emphasizes the use of evidence-based knowledge and practice with diverse knowledge-user groups. In addition, KT is uniquely designed and tailored to each specific user and context (Sudsawad, 2007). These different aspects of KT play a dynamic role in the development and implementation of the different KT strategies.

Effective vocational rehabilitation outcomes involve participation in the knowledge-to-action (KTA) process by multiple stakeholders: consumers and their families, the rehabilitation practitioners, rehabilitation educators and researchers, administrator and policy makers, and business and industry. Therefore, satisfaction with the implementation and utilization of knowledge translation (KT) is vital. The steps, from knowledge creation to its application into practice, will require KT to be uniquely designed and tailored to each specific user and context (Sudsawad, 2007). 


\subsection{Importance of organization and leaders in supporting $K T$}

Engagement in knowledge translation and support for evidence-based practice cannot take place at the individual or practitioner level alone. For KT to have a lasting impact, it needs to become part of institutional practice (Stetler, 2003). Cultivating an evidence-based approach to practice requires a change in thinking and cultural shift for vocational rehabilitation agencies more broadly. Many barriers exist at levels beyond individual practitioners, including team and social environments, organizations, or broader inter-organizational environments (YousefiNooraie, Dobbins, \& Marin, 2014). Presence of an organizational structure or work culture that does not value or promote research utilization will undermine individual practitioner interest in acquiring, applying, and sharing evidence-based practices and therefore must be addressed early (Kitson, Ahmed, Harvey, Seers, \& Thompson, 1996; Sitzia, 2002).

Aligning system and organizational structures with evidence-based practices is complex and needs to engage administrators, policymakers, state planners, and managers of service provider agencies (Kerner, 2006). Importantly, organizations that explicitly bridge research and service within their mission do a better job of promoting and supporting both knowledge translation activities and evidence-based practices (Kerner, 2006).

Facilitators and barriers of knowledge translation and evidence-based practice exist at the organizational as well as the individual level. Factors such as lack of access to research, poor dissemination, cost, lack of managerial support, professional bodies, managerial staff turnover, poor long-term policy planning, and inflexible or non-transparent policy processes were noted as frequent barriers to EBP implementation within agencies (Baumbusch et al., 2008; Glasgow \& Emmons, 2007; Oliver et al., 2014). The most frequently reported facilitators include: access to and improved dissemination of research, existence of and access to relevant research, organizational commitment to knowledge translation, and collaborative relationships between policymakers and research staff (Baumbusch et al., 2008; Oliver et al., 2014).

Researchers need to work with key staff or opinion leaders at the organizational level to shift organizational culture through policy and procedure (Baumbusch et al., 2014; Glasgow \& Emmons, 2007). 'Opinion leaders' typically hold strategic positions within an organization, are able to informally affect others' attitudes and behaviors in a desired way, and are suitable candidates to be chosen as early adopters of KT interventions (Flodgren et al., 2011). Opinion leaders alone or in combination with other interventions may successfully promote evidence-informed practice and KT developers should actively identify opinion leaders and engage them as the agents of change in the organization (Flodgren et al., 2011).

Currently, VR agencies are somewhat passive in adopting evidence-based practices and tend not to expect counselors to review and use EBP in their duties and provide limited incentives for them to do so (Graham et al., 2013). However, agency leaders and managers have a tremendous opportunity to influence organizational culture and support practitioner engagement in knowledge translation and evidence-based practice. Involving leaders and managers as partners for promoting evidence-informed decision making and evidence-based practice is key in enhancing early adoption of new KT knowledge and skills within organizations and is an important factor contributing to the success of KT interventions (Oliver et al., 2014; Yousefi-Nooraie et al., 2014).

\subsection{Knowledge mobilization $(K M b)$}

Knowledge translation and mobilization approaches that are considered most effective involve sustained multilevel approaches including practitioner choice, skill-based training, practice-based coaching, practitioner performance evaluation, program evaluation, supportive administrative practices, and methods for system interventions (Kerner, 2006). The adoption of knowledge mobilization (KMb) will advance the knowledge-to-action process to further address issues related to accessing, applying, and sharing information within the knowledge translation frameworks (Estabrooks et al., 2008).

\section{Conclusions}

Rehabilitation scholars must actively integrate contemporary knowledge translation and mobilization strategies into research, thereby effectively providing tools for counselors to adopt in practice. The goals of comprehensively embedding evidence-based practice into the state-federal vocational rehabilitation programs can be achieved through active and ongoing cooperation and collaboration between researchers, practitioners, and administrators. 


\section{Acknowledgments}

The contents of this article were developed with support from the Rehabilitation Research and Training Center on Evidence-Based Practice in Vocational Rehabilitation (RRTC-EBP VR) at the University of Wisconsin-Madison and the University of WisconsinStout and with funding provided by the U.S. Department of Education, National Institute on Disability and Rehabilitation Research (Grant H133B100034). The ideas, opinions, and conclusions expressed, however, are those of the authors and do not represent recommendations, endorsements, or policies of the U.S. Department of Education.

\section{References}

Anderson, C. A., Matthews, P. R., Lui, J. \& Nierenhausen, E. (in press). Engaging vocational rehabilitation counselors in knowledge translation processes: A participatory action approach. Rehabilitation Counselors and Educators Journal.

Baumbusch, J. L., Kirkham, S. R., Khan, K. B., McDonald, H., Semeniuk, P., Tan, E. \& Anderson, J. M. (2008). Pursuing common agendas: A collaborative model for knowledge translation between research and practice in clinical settings. Research in Nursing and Health, 31, 130-140.

Bezyak, J. L., Kubota, C. \& Rosenthal, D. (2010). Evidenced-based practice in rehabilitation counseling: Perceptions and practice. Rehabilitation Education, 24(1-2), 85-96.

Chan, F., Bezyak, J., Ramirez, M., Chiu, C., Sung, C. \& Fujikawa, M. (2010). Concepts, challenges, barriers, and opportunities related to evidence-based practice in rehabilitation counseling. Rehabilitation Education, 24, 179-190.

Chan, F., Sung, C., Muller, V., Wang, C., Fujikawa, M. \& Anderson, C. (2011). Chapter 18: Evidence-based practice and research utilization. The professional practice of rehabilitation counseling (p. 389-410). Springer Publishing Company.

Coppock, E. G. \& Davis, L. (2013). Status of the adoption of social media in the scientific research community. Information Services \& Use, 33, 203-217. doi:10.3233/ISU-130711

Dev, S. \& Schultz, D. (2005a). A customer-focused approach can bring the current marketing mix into the 21 st century. Marketing Management, 14(1), 16-22.

Dev, S. \& Schultz, D. (2005b). Simply SIVA. Marketing Management, 14(2), 36-42.

Estabrooks, C., Derksen, L., Winther, C., Lavis, J., Scott, S., Wallin, R. \& Profetto-McGrath, J. (2008). The intellectual structure and substance of the knowledge utilization field: A longitudinal author co-citation analysis, 1945 to 2004. Implementation Science, 2(49). doi:10.1186/1748-5908-3-49

Flodgren, G., Parmelli, E., Doumit, G., Gattellari, M., O’Brien, M., Grimshaw, J. \& Eccles, M. (2011). Local opinion leaders: Effects on professional practice and health care outcomes. Cochrane Database System Revised, 8. Art. No.: CD000125. doi: $10.1002 / 14651858$
Glasgow, R. \& Emmons, K. (2007). How can we increase translation of research into practice? Types of evidence needed. Annual Review Public Health, 28, 413-433.

Graham, C., Inge, K., Wehman, P., Murphy, K., Revell, W. \& West, M. (2013). Moving employment research into practice: Knowledge and application of evidence-based practices by state and vocational rehabilitation agency staff. Journal of Vocational Rehabilitation, 39, 75-81.

Graham, I. D., Logan, J., Harrison, M. B., Straus, S. E., Tetroe, J., Caswell, W. \& Robinson, N. (2006). Lost in knowledge translation: Time for a map? The Journal of Continuing Education in the Health Professions, 26, 13-24.

Grol, R. (2001). Successes and failures in the implementation of evidence-based guidelines for clinical practice. Medical Care, 39(8, Suppl. 2), II46-54.

Grol, R. \& Grimshaw, J. (2003). From best evidence to best practice: Effective implementation of change in patients' care. The Lancet, 362(9391), 1225-1230.

Hergenrather, K., Geishecker, S., McGuire-Kuletz, M., Gitlin, D. \& Rhodes, S. (2010). An introduction to community-based participatory research. Rehabilitation Education, 24, 225-238.

Jacobson, N., Butterill, D. \& Goering, P. (2003). Development of a framework for knowledge translation: Understanding user context. Journals of Health Services \& Research Policy, 8, 94-99.

Kerner, J. F. (2006). Knowledge translation versus knowledge integration: A funder's perspective. The Journal of Continuing Education in the Health Professions, 26(1), 72-80.

Kitson, A., Ahmed, L., Harvey, G., Seers, K. \& Thompson, D. (1996). From research to practice: One organizational model for promoting research-based practice. Journal of Advanced Nursing, 23, 430-440.

Marshall, M. V. (1984). An introduction to the marketing concept of managing an institution's future. Cambridge, MA: Institute for Education Management.

Martin, D. \& Martin, M. (1989). Current trends: Bridging the gap between research and practice. Journal of Counseling \& Development, 87, 108-116.

McCarthy, E. J. (1960). Basic marketing: A managerial approach. Homewood, IL: Richard D. Irwin.

McWilliam, C. L. (2007). Continuing education at the cutting edge: Promoting transformative knowledge translation. Journal of Continuing Education in the Health Professions, 27(2), 72-79.

Menon, A., Korner-Bitensky, N., Kastner, M., McKibbon, K. \& Straus, S. (2009). Strategies for rehabilitation professionals to move evidence-based knowledge into practice: A systematic review. Rehabilitation Medicine, 41, 1024-1032.

Oliver, K., Innvar, S., Lorenc, T., Woodman, J. \& Thomas, J. (2014). A systematic review of barriers to and facilitators of the use of evidence by policymakers. BioMed Central Health Services Research, 14(2). Retrieved from http://www.biomedcentral.com/1472-6963/14/2

Pettus-Davis, C., Grady, M. D., Cuddeback, G. S. \& Scheyett, A. (2011). A practitioner's guide to sampling in the age of evidencebased practice: Translation of research into practice. Clinical Social Work Journal, 39, 379-389.

Pfeffer, J. \& Salancik, G. (1978). The external control of organizations: A resource dependence perspective. New York, NY: HarperCollins.

Schünemann, H. J., Oxman, A. D., Higgins, J. P. T., Vist, G. E., Glasziou, P. \& Guyatt, G. H. (2011). Chapter 11: Presenting results and 'Summary of findings' tables. In: Higgins J. P. T. \& 
Green S. (Eds.), Cochrane Handbook for Systematic Reviews of Interventions Version 5.1.0 (updated March 2011). The Cochrane Collaboration. Retrieved from www.cochrane-handbook.org

Seaman, M. (2008). Birds of a feather? Communities of practice and knowledge communities. Curriculum and Teaching Dialogue, 10 (1 \& 2), 269-279.

Sitzia, J. (2002). Barriers to research utilization: The clinical setting and nurses themselves. Intensive \& Critical Care Nursing, 18, 230-243.

Stetler, C. B. (2003). Role of the organization in translating research into evidence-base practice. Nursing Outlook, 49, 272-279.

Sudsawad, P. (2007). Knowledge translation: Introduction to models, strategies, and measures. Austin, TX: Southwest Educational
Development Laboratory, National Center for the Dissemination of Disability Research.

U.S. Department of Education Office (2006). The National Institute on Disability and Rehabilitation Research-Notice of final longrange plan for fiscal years 2005-2009, Fed. Reg. 31, 8165-8200.

Wenger, E., McDermott, R. \& Snyder, W. M. (2002). A guide to managing knowledge: Cultivating communities of practice. Boston, MA: Harvard Business School Press.

Yousefi-Nooraie, R., Dobbins, M. \& Marin, A. (2014). Social and organizational factors affecting implementation of evidenceinformed practice in a public health department in Ontario: A network modeling approach. Implementation Science, 9(29). doi: 10.1186/1748-5908-9-29 